\title{
Die Sicherung der Energieversorgung auf globalisierten Märkten
}

\author{
Hrsg. v. Stefan Leible, Michael Lippert u. Christian Walter
}

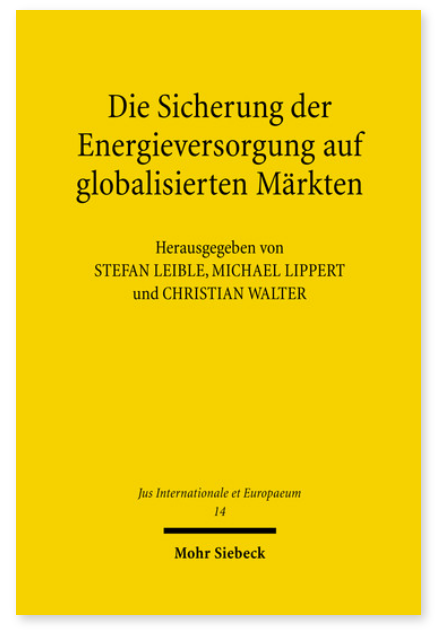

2007. XII, 184 Seiten. JusIntEu 14

ISBN 978-3-16-151153-0

DOI 10.1628/978-3-16-151153-0

eBook PDF 59,00€

ISBN 978-3-16-149387-4

fadengeheftete Broschur 59,00€
Die Sicherung der Energieversorgung im weltweiten Maßstab wird in Zukunft zentrale Bedeutung erlangen. Nach der Einschätzung des Generalsekretärs der Organisation Erdölexportierender Länder (OPEC) werden 4/5 des Wachstums der Ölnachfrage in den nächsten zwei Dekaden aus Entwicklungsländern kommen, deren Konsum sich verdoppeln wird. Der aus dem nationalen Energierecht bekannte Grundsatz der »Versorgungssicherheit« wird damit vor neue Herausforderungen gestellt. Ausgehend von einer Analyse der strategisch-politischen Rahmenbedingungen untersuchen die Autoren der Beiträge im vorliegenden Band die Steuerungsmöglichkeiten des Rechts auf den verschiedenen Stufen der Versorgungskette, also von der Rohstoffgewinnung bis zur Versorgung des Endverbrauchers. Dies geschieht auf der Ebene des internationalen, des europäischen und des nationalen Rechts. Konkret untersucht werden das europäische und nationale Regulierungsverwaltungsrecht, das internationale Investitionsschutzrecht, das Welthandelsrecht, das private internationale Wirtschaftsrecht und das Kartellrecht. Im Vordergrund steht dabei nicht nur der Streit um Umfang und Grenzen einer Liberalisierung der Energieversorgung, sondern die Autoren beziehen auch in rechtspolitischen Debatten Stellung, wie etwa derjenigen um den richtigen »Energiemix« und die Zukunft der Kernenergie.

\section{Inhaltsübersicht}

Michael Lippert: Sicherheit der Energieversorgung: Renaissance eines energierechtlichen Leitziels? - Friedemann Müller: Strategische Bedingungen für die Nutzung der Weltenergiereserven: Energiesicherheit und internationale Sicherheitspolitik Christian Walter: Gewährleistungs- und Erfüllungsverantwortung auf globalen Energiemärkten. Brauchen wir eine »Rohstoffbeschaffungsverantwortung«? - Ulrich Ehricke: Equity-Joint Venture-Verträge als Instrument zur Sicherung der Versorgung mit ausländischen Energieträgern - Helga Steeg: Erschließung ausländischer Energiereserven und Investitionsschutz - Frank Schorkopf: »Energie« als Thema des Welthandelsrechts - Michael Fehling: Energieversorgung zwischen Daseinsvorsorge und internationaler Liberalisierung - Mathias Wolkewitz: Rechtssichere Gestaltung von internationalen Energielieferungsverträgen - Wulf-Henning Roth: Kartellrecht als Instrument der sicheren Energieversorgung - Carsten Schmidt: Diskussionsbericht: Erneuerbare Energien und sichere Energieversorgung

Christian Walter ist Professor für Völkerrecht und Öffentliches Recht an der Universität München.

Stefan Leible ist Inhaber des Lehrstuhls für Zivilrecht, Internationales Privatrecht und Rechtsvergleichung an der Universität Bayreuth und Präsident der Universität Bayreuth.

Michael Lippert ist Rechtsanwalt und Honorarprofessor für Energiewirtschaftsrecht an der Universität Jena.

Jetzt bestellen:

https://mohrsiebeck.com/buch/die-sicherung-der-energieversorgung-auf-globalisierten-maerkten-9783161511530? no_cache=1

order@mohrsiebeck.com

Telefon: +49 (0)7071-923-17

Telefax: $+49(0) 7071-51104$ 